\title{
Genome-Wide Association Study in Thai Tsunami Survivors Identified Risk Alleles for Posttraumatic Stress Disorder
}

\author{
Nuntika Thavichachart ${ }^{1 *}$, Taisei Mushiroda ${ }^{2}$, Thongchai Thavichachart ${ }^{3}$, \\ Ongart Charoensook ${ }^{3}$, Anchalee Prasansuklab ${ }^{1,4}$, Prathan Rutchatajumroon ${ }^{3}$, \\ Sookjaroen Tangwongchai', Puangsoi Worakul', Buranee Kanchanatawan', \\ Siriluck Suppapitiporn'1, Atapol Sughondhabirom ${ }^{1}$, Chutima Roomruangwong 1 , \\ Wasun Chantratita ${ }^{5}$, Atsushi Takahashi6, Michiaki Kubo ${ }^{7}$, Naoyuki Kamatani6, \\ Yusuke Nakamura ${ }^{8}$ \\ ${ }^{1}$ Department of Psychiatry, Faculty of Medicine, Chulalongkorn University, Bangkok, Thailand \\ ${ }^{2}$ Laboratory for Pharmacogenetics, RIKEN Center for Genomic Medicine, Kanagawa, Japan \\ ${ }^{3}$ Thailand Center of Excellence for Life Sciences (Public Organization), Ministry of Science and Technology, \\ Bangkok, Thailand \\ ${ }^{4}$ Ph.D. Program in Clinical Biochemistry and Molecular Medicine, Department of Clinical Chemistry, Faculty of \\ Allied Health Sciences, Chulalongkorn University, Bangkok, Thailand \\ ${ }^{5}$ Department of Pathology, Faculty of Medicine, Mahidol University, Bangkok, Thailand \\ ${ }^{6}$ Laboratory for Statistical Analysis, RIKEN Center for Genomic Medicine, Kanagawa, Japan \\ ${ }^{7}$ Laboratory for Genotyping Development, RIKEN Center for Genomic Medicine, Kanagawa, Japan \\ ${ }^{8}$ Laboratory of Molecular Medicine, Human Genome Center, Institute of Medical Science, The University of \\ Tokyo, Tokyo, Japan \\ Email: ${ }^{*}$ nuntika.th@gmail.com
}

Received 30 April 2015; accepted 8 June 2015; published 11 June 2015

Copyright (C) 2015 by authors and Scientific Research Publishing Inc.

This work is licensed under the Creative Commons Attribution International License (CC BY).

http://creativecommons.org/licenses/by/4.0/

c) (†) Open Access

\section{Abstract}

Posttraumatic stress disorder (PTSD) is a psychiatric disorder found in individuals afflicted by a traumatic event. Multiple environmental and genetic factors can contribute to PTSD susceptibility. Since it is rare to find members of the same family afflicted by the same catastrophic event, it is not practical to determine PTSD susceptibility genes by a gene linkage analysis. A natural disaster, such as the 2004 Tsunami, provided us with a rare chance for a genetic analysis of PTSD. To identify SNPs associated with PTSD susceptibility, we conducted a genome-association study (GWAS) in Thai-Tsunami survivors. Initial phase of the study with 396 chronic PTSD patients and 457 controls, we identified top ninety SNPs $\left(P<1 \times 1^{-4}\right)$, which were further assessed in the second phase

${ }^{*}$ Corresponding author.

How to cite this paper: Thavichachart, N., et al. (2015) Genome-Wide Association Study in Thai Tsunami Survivors Identified Risk Alleles for Posttraumatic Stress Disorder. Open Journal of Genetics, 5, 43-57.

http://dx.doi.org/10.4236/ojgen.2015.52004 
with 395 chronic PTSD patients and 798 controls. Two SNPs (rs267950 and rs954406), were identified in the second phase, and subjected to fine mapping using a data set from both phases. SNP rs267943 showed the strongest association with PTSD susceptibility and was in complete linkage disequilibrium with SNP rs267950 with $P=6.15 \times 10^{-8}$, $O R=1.46$ and $95 \% \mathrm{CI}=1.19-1.79$, reaching genome-wide significance. SNP rs267943 is located on chromosome 5 in the intron of the death-associated protein 1 (DAP1) gene and, when linked to a synthetic promoter, could regulate transcription. To our knowledge, this is the first GWAS for PTSD susceptibility in an Asian population which could provide an important insight into the genetic contribution of PTSD and may lead to new treatment strategies for PTSD.

\section{Keywords}

Death-Associated Protein 1 Gene (DAP1), Genetics, Genome-Wide Association Study (GWAS), Posttraumatic Stress Disorder (PTSD), Tsunami

\section{Introduction}

Posttraumatic stress disorder (PTSD) is a psychiatric disorder with debilitating consequences that has gained much interest in recent years. PTSD settles in and stays with an individual for a long period of time making it difficult for an individual with PTSD to live a normal life and return to the society. PTSD affects an individual after experiencing or witnessing a traumatic or life-threatening event such as major natural or man-made disasters including earthquakes, hurricanes, major floods, tsunami or wars. Individuals afflicted by PTSD can be categorized into three major groups according to their symptoms including re-experiencing, avoidance and hyperarousal. Not all individuals who experienced or witnessed a traumatic event will develop PTSD. Some may only experience PTSD-like symptoms for a short period of time. However, an individual is likely to be diagnosed with PTSD if the symptoms persist for longer than one month. PTSD can be further sub-categorized into two groups, acute and chronic PTSD, according to the length of time taken to resolve PTSD-related symptoms. Acute PTSD usually takes less than three month whereas chronic PTSD usually takes more than three months to resolve. The prevalence of PTSD after a natural disaster ranged from as low as $22.3 \%$ to as high as $78 \%$ [1]-[3], while the prevalence of PTSD after a war or a man-made disaster ranged from $2 \%$ to $17 \%$ [4]. Due to an increase in political unrests in numerous regions around the world today, it is likely that more and more people will be affected by PTSD. Therefore, a better understanding of PTSD pathogenesis may help identify and prevent susceptible individuals from developing the disease and may lead to better diagnostics and treatments of PTSD.

Similar to many psychiatric disorders, PTSD is a complex and multifactorial psychiatric disorder. Multiple environmental and genetic factors, including sex, age, the severity of the traumatic event [5] [6], hormone levels [7], history of mental illnesses, and childhood trauma [8] [9], have been reported to influence the development of PTSD. In this study, we seek to determine whether genetic factors could be involved in PTSD susceptibility. Several studies suggested the contribution of genetic factors in the pathogenesis of PTSD. True W., et al. reported that genetic factors accounted for $13 \%-34 \%$ of a variation in PTSD symptoms [10]. Similar results were found in a study of PTSD symptoms in identical twins [11]. Together, these studies suggest that genetic factors may play a significant role in the pathogenesis of PTSD.

Furthermore, increasing numbers of studies identified candidate genes that could be important for PTSD susceptibility. These candidate genes include genes that are involved in both neurotransmitter system, such as dopamine [12] [13], serotonin [14]-[17] and gamma-aminobutyric acid (GABA) [18], and non-neurotransmitter, such as glucocorticoid [19]-[21]. The candidate gene approach has gained popularity in recent years leading to identification of several PTSD susceptibility genes. However, these PTSD susceptibility genes remain controversial and inconsistent due to variations in several parameters including sample size, ethnicity, type of traumatic event, experimental design and data analysis [15] [17] [22] [23]. In addition, PTSD susceptibility genes are unlikely to express in general population since individuals are only affected by PTSD after exposure to a traumatic event, making it challenging to design a genetic study in search for PTSD susceptibility genes. It is also 
impractical to perform family linkage analysis for PTSD since it is extremely rare to find individuals from the same family experiencing or witnessing similar traumatic events. Because of these limiting factors, how genetic factors contribute to the development of PTSD remains poorly understood.

A natural disaster brings about destruction and trauma to a population as a whole. One of the most devastating and deadliest natural disasters in recent history took place on December 26, 2004. An earthquake, with a magnitude 9.0 on Richter scales with an epicenter off the northwest coast of Sumatra, Indonesia, triggered a series of tsunami along the coast of landmasses around the Indian Oceana and the Andaman Sea, claiming an estimated of 300,000 lives. In Thailand, several popular coastal resort cities along the Andaman Sea including Phuket and KhaoLak, were badly hit, killing an estimate of 8000 lives. This tragic and devastating event not only caused tremendous loss of lives and properties. Many of the 2004 tsunami survivors suffered from a variety psychiatric conditions especially PTSD. A survey, carried out six-month after the 2004 tsunami, showed that the prevalence of chronic and lifetime PTSD of the 2004 tsunami survivors were $21.6 \%$ and $3.9 \%$, respectively [24]. The devastation and trauma of the 2004 tsunami touched thousands of lives along the coast of the Andaman Sea in Thailand providing us with a rare opportunity to conduct genetic analysis for PTSD. We hypothesized that PTSD susceptibility was associated with at least one or more genetic variants or SNPs in the genome. A large number of the 2004 tsunami survivors enabled us to conduct a Genome-Wide Association Study (GWAS) in over two thousands of individuals from six provinces along the coast of the Andaman Sea in south Thailand and determine whether any genetic variants or SNPs were associated with the onset of chronic PTSD.

\section{Materials and Methods}

\subsection{Subjects}

This study was approved by The Ethical Review Committee for Research in Human Subjects, Ministry of Public Health, Thailand and The Institutes of Physical and Chemical Research (RIKEN), Yokohama, Japan. The informed consents were obtained from all study participants. All of participants were Thai volunteers aged over 18 years old who were born and living in the southern provinces of Thailand that was hit by the Tsunami including Pang-nga, Ranong, Phuket, Krabi, Trang, and Satoon. They must have, at least 3 generations, their ancestors with Southeast Asian appearances. The chronic PTSD cases used in this study were selected from subjects who suffered of PTSD longer than six months or, in other words, who diagnosed with PTSD at both phases of cross-sectional community survey. In turn, the subjects who not affected with PTSD at least six months aftermath were defined as controls. We excluded the subjects in severe physical and mental conditions that cannot communicate during the interviewing process.

Cross-sectional community surveys were conducted in two phases with a set of standard structured questionnaires to determine chronic PTSD cases and controls. The protocols and procedures of both phases have been previously described [24]. All instruments used in this study had been translated and tested for good cultural validity and reliability. The data of first phase study was collected within three months after the Tsunami disaster in 2004. The subjects were interviewed by well-trained nursing students using Davidson Trauma Scale (DTS), commonly used screening test for PTSD, [25] and Clinician-Administered PTSD Scale (CAPS-2), clinical interviewed for diagnosis of PTSD [26]. The subjects from the first phase were re-interviewed with Structured Assessment for Drug Dependence and Alcoholism (SADDA), structured interview for genetic study, [27] to determine life time prevalence and chronic PTSD. Moreover, two other questionnaires; Diagnostic Interview for Genetic studies (DIGS), used for getting genetic and heredity information [28] and Composite International Diagnostic Interview (CIDI), used for community diagnosis of mental disorders [29] [30], were conducted in the second phase to determine co-morbidity and to exclude other psychological disorders including drug abused, bipolar disorders, anxiety disorders. The interviewers in this phase were well-trained psychologists whose interrater reliability has checked among them. Monitoring the performance of the interviewers of both phases by psychiatrists was done along the data collection process to ensure the highest quality of the obtained clinical data. Blood samples from every subject were also collected in this phase for genetic study. All questionnaires and assessment forms were tested for cultural validity and reliability [24].

The total 2046 subjects who met the criteria described above were included in this study and divided into two independent case-control sample sets. The first sample set containing 396 individuals diagnosed with chronic PTSD and 457 non-affected controls were used for GWAS analysis. Then P-values from GWAS analysis of the first sample set was confirmed by the additional second set of samples containing the rest subjects, 395 chronic 
PTSD cases and 798 unaffected controls, used as replication samples to verify a possible association in the initial screening. Demographic characteristics were summarized in Table 1 for samples that were included in the analyses.

\subsection{SNP Genotyping and Case-Control Association Study}

Genomic DNA was extracted from peripheral blood leucocytes by using QIAamp DNA Mini QIAcube Kit (Qiagen, Hilden, Germany). The concentrations of genomic DNA of all samples extracted were measured with ND-1000 (NanoDrop Technologies, Wilmington, DE). A genome-wide genotyping for 396 cases and 457 controls was conducted using Illumina Human-Hap610 Genotyping BeadChip according to the manufacturer's protocols (Illumina, San Diego, CA). A principal component analysis (PCA) was performed by an "Eigen analysis” using smartpca program in the EIGENSOFT package [31] for evaluating and correcting the effect of population stratification in our samples which might affect the results and interpretation of a genetic association study. Genotype data for the cases and controls and general population subjects for 89 East-Asian individuals (44 Japanese and 45 Han Chinese) from the International HapMap project (2003) were subjected to PCA analyses. PCA plots were obtained by plotting the first two principal components (Eigenvectors 1 and 2) from our data with those from reference samples of East-Asian ethnicities. An observation plot that significantly deviated from other samples was identified as outlier and excluded from the data set. The genotyping results were validated by multiplex PCR-based Invader assays (Third Wave Technologies, Madison, WI) [32] and/or direct sequencing of PCR products using a 96-capillary 3730xl DNA Analyzer (Applied Biosystems, Foster City, CA). Data between platforms were compared. For the quality control of our whole-genome genotyping data, SNPs on autosomal chromosomes with the genotype call rate higher than 0.99 , SNPs with minor allele frequency higher than 0.00 or SNPs with a P-value of deviation from Hardy-Weinberg equilibrium (PHWE) higher than 0.000001 in controls were selected for further analysis. The genotype call rate was defined for each SNP as the fraction of samples successfully genotyped over the total number of samples genotyped. The sample call rate was defined for each subject as the fraction of successfully genotyped SNPs per sample over the total number of SNPs in the dataset. In addition, SNPs located on mitochondrial DNA or on X and Y chromosomes were excluded. To search for a rare variation which GWAS was not well powered to detect, we re-sequenced relevant region of candidate SNPs in sixteen pooled DNA samples (three subjects per sample) using BigDye ${ }^{\circledR}$ Terminator cycle sequencing kit and a 96-capillary 3730xl DNA Analyzer (Applied Biosystems, Foster City, CA).

\subsection{Assessing Transcriptional Activity of rs267943 Using the Luciferase Assay}

We constructed two plasmid constructs containing a copy of 41-bp oligonucleotides, which included either the risk allele "G” or non-risk allele “A” of SNP rs267943 (Table 2) along with additional twenty base pairs flanking the allele with $\mathrm{XhoI}$ and BglII restriction sites at 5' and 3'-end, respectively. The nucleotide sequence of oligonucleotide containing risk $\mathrm{G}$ allele is "TTGTGGCCAC TGAGCAACCA GAACCTTTCC AGCTGGTCCC C" and the sequence of oligonucleotide for the non-risk A allele is "TTGTGGCCAC TGAGCAACCA AAACCTTTCC AGCTGGTCCC C”. Each oligonucleotide was cloned into the XhoI/BglII sites upstream of SV40 promoter in pGL4 vector (Promega, Madison, WI). Sequences of all constructs were confirmed by direct DNA

Table 1. Sample characteristics.

\begin{tabular}{|c|c|c|c|c|c|c|}
\hline \multirow{3}{*}{ Characteristic } & \multicolumn{2}{|c|}{$1^{\text {st }}$ sample set (GWAS) } & \multicolumn{2}{|c|}{$2^{\text {nd }}$ sample set (Replication) } & \multicolumn{2}{|c|}{ Total } \\
\hline & Cases & Controls & Cases & Controls & Cases & Controls \\
\hline & $(n=396)$ & $(n=457)$ & $(n=395)$ & $(\mathrm{n}=798)$ & $(\mathrm{n}=791)$ & $(\mathrm{n}=1255)$ \\
\hline \multicolumn{7}{|l|}{ Sex, n (\%) } \\
\hline Female & $247(62.4)$ & $280(61.3)$ & $249(63.0)$ & $453(56.8)$ & $496(62.7)$ & $733(58.4)$ \\
\hline Male & 149 (37.6) & $177(38.7)$ & $146(37.0)$ & $345(43.2)$ & 295 (37.3) & $522(41.6)$ \\
\hline Mean age in years (S.D.) & $39.0(12.9)$ & $40.0(13.1)$ & $37.3(13.0)$ & $41.2(14.8)$ & $38.2(13.0)$ & $40.8(14.2)$ \\
\hline
\end{tabular}

GWAS, Genome-wide association study; S.D., Standard deviation. 
Table 2. Summary of association results of SNPs in complete linkage disequilibrium (LD) with the rs267950.

\begin{tabular}{|c|c|c|c|c|c|c|c|c|c|c|c|c|c|c|c|}
\hline \multirow{2}{*}{ SNP ID } & \multirow{2}{*}{ Position $^{\mathrm{a}}$} & \multirow{2}{*}{$\begin{array}{c}\text { Allele }^{\mathrm{b}} \\
(1 / 2)\end{array}$} & \multicolumn{4}{|c|}{ Case } & \multicolumn{4}{|c|}{ Control } & \multirow{2}{*}{$\begin{array}{l}\text { Risk } \\
\text { allele }\end{array}$} & \multirow{2}{*}{$\begin{array}{c}\text { P-value } \\
\text { minimum }^{c}\end{array}$} & \multirow{2}{*}{$\begin{array}{l}\text { Odds } \\
\text { ratio }\end{array}$} & \multirow{2}{*}{$\begin{array}{l}\text { P-value } \\
\text { MH-P }\end{array}$} & \multirow{2}{*}{$\begin{array}{l}\text { Odds } \\
\text { ratio }^{\circ}\end{array}$} \\
\hline & & & 11 & 12 & 22 & MAF & 11 & 12 & 22 & MAF & & & & & \\
\hline rs379711 & 10748380 & $\mathrm{C} / \mathrm{T}]$ & 406 & 320 & 65 & 4 & 766 & 428 & 57 & 7 & $\mathrm{~T}$ & $1.09 \mathrm{~F}$ & 1.50 & $9.95 \mathrm{E}-07$ & 1.44 \\
\hline rs3797117 & 10749280 & {$[\mathrm{~A} / \mathrm{G}]$} & 402 & 322 & 66 & 37 & 765 & 427 & 57 & 7 & G & & 1.53 & -07 & 1.47 \\
\hline rs3756405 & 10752771 & {$[\mathrm{C} / \mathrm{G}]$} & 406 & 317 & 68 & 0.286 & 763 & 423 & 63 & 0.220 & G & $1.74 \mathrm{E}-06$ & 1.49 & $1.69 \mathrm{E}-06$ & 1.43 \\
\hline rs375 & 514 & {$[\mathrm{~A} / \mathrm{G}]$} & 401 & 322 & 67 & .289 & 757 & 435 & 57 & 0.220 & G & $8.30 \mathrm{E}-07$ & 1.49 & $6.71 \mathrm{E}-07$ & 1.45 \\
\hline rs267987 & 10765624 & [G/A] & 311 & 368 & 111 & 0.373 & 615 & 523 & 113 & 0.299 & A & $1.15 E-06$ & 1.49 & $5.52 \mathrm{E}-07$ & 1.41 \\
\hline rs267979 & 10772132 & [T/C] & 309 & 368 & 111 & 0.374 & 611 & 520 & 114 & 0.300 & C & $1.14 \mathrm{E}-06$ & 1.49 & $4.97 \mathrm{E}-07$ & 1.42 \\
\hline rs267977 & 10773879 & {$[\mathrm{~A} / \mathrm{T}]$} & 308 & 368 & 112 & 0.376 & 614 & 521 & 115 & 0.300 & $\mathrm{~T}$ & $8.18 \mathrm{E}-07$ & 1.50 & $9 \mathrm{E}-07$ & 1.42 \\
\hline rs267974 & 10776467 & {$[\mathrm{G} / \mathrm{C}]$} & 308 & 371 & 112 & 0.376 & 612 & 523 & 114 & 0.301 & C & $7.11 \mathrm{E}-07$ & 1.51 & $2.87 \mathrm{E}-07$ & 1.42 \\
\hline rs413846 & 10785289 & {$[\mathrm{C} / \mathrm{T}]$} & 309 & 368 & 111 & 0.374 & 608 & 522 & 111 & 0.300 & $\mathrm{~T}$ & $9.34 \mathrm{E}-07$ & 1.49 & $4.06 \mathrm{E}-07$ & 1.42 \\
\hline rs393291 & 10785625 & [G/A] & 303 & 371 & 117 & 0.382 & 596 & 541 & 115 & 0.308 & A & $1.16 \mathrm{E}-06$ & 1.46 & $4.36 \mathrm{E}-07$ & 1.41 \\
\hline rs382031 & 10786749 & {$[\mathrm{G} /$} & 31 & 370 & 109 & 0.3 & 6 & 523 & 112 & 0 & A & 1.6 & 1.49 & 07 & 1.41 \\
\hline rs394407 & 10787081 & {$[\mathrm{G} / \mathrm{C}]$} & 312 & 368 & 110 & 0.372 & 616 & 520 & 113 & 0.299 & C & $1.34 \mathrm{E}-06$ & 1.49 & $5.85 \mathrm{E}-07$ & 1.41 \\
\hline rs267957 & 10791444 & {$[\mathrm{C} / \mathrm{T}]$} & 306 & 367 & 118 & 0.381 & 598 & 532 & 121 & 0.309 & $\mathrm{~T}$ & $2.71 \mathrm{E}-06$ & 1.45 & $1.08 \mathrm{E}-06$ & 1.41 \\
\hline rs267952 & 10796135 & {$[\mathrm{~A} / \mathrm{G}]$} & 309 & 369 & 112 & 0.375 & 619 & 521 & 112 & 0.2 & G & $2.80 \mathrm{E}-07$ & 1.52 & $1.41 \mathrm{E}-07$ & 1.44 \\
\hline rs267947 & 10798946 & {$[\mathrm{~A} / \mathrm{G}]$} & 311 & 369 & 111 & 0.374 & 617 & 520 & 113 & 0.298 & G & $6.87 \mathrm{E}-07$ & 1.50 & $3.49 \mathrm{E}-07$ & 1.42 \\
\hline rs267944 & 10801231 & {$[\mathrm{~T} / \mathrm{C}]$} & 307 & 372 & 112 & 0.377 & 613 & 521 & 114 & 0.300 & C & $4.95 \mathrm{E}-07$ & 1.52 & $2.10 \mathrm{E}-07$ & 1.43 \\
\hline rs267943 & 10801462 & {$[\mathrm{~A} / \mathrm{G}]$} & 314 & 369 & 107 & 0.369 & 627 & 514 & 104 & 0.290 & G & $1.60 \mathrm{E}-07$ & 1.54 & $6.15 E-08$ & 1.46 \\
\hline rs267940 & 10804862 & {$[\mathrm{~T} / \mathrm{C}]$} & 315 & 369 & 106 & 0.368 & 615 & 519 & 112 & 0.298 & $\mathrm{C}$ & $4.21 \mathrm{E}-06$ & 1.47 & $2.22 \mathrm{E}-06$ & 1.39 \\
\hline
\end{tabular}

Chromosome: 5; Gene: DAP, Location: intron, Overall 95\% CI between 1.13 - 1.89. CI, confidence interval; DAP, death-associated protein; MAF, minor allele frequencies; MH; Mantel-Haenszelmethod; SNP, single nucleotide polymorphism. ${ }^{\mathrm{a} F r o m ~ N a t i o n a l ~ C e n t e r ~ f o r ~ B i o t e c h n o l o g y ~ I n f o r m a t i o n ~}$ (NCBI) build 36.3 reference; ${ }^{b}$ The second allele represents the minor allele; 'The minimum P-value of Fisher's exact test for three models (dominant, recessive and allelic models); ${ }^{\mathrm{D}} \mathrm{P}$-values and odd ratio for meta-analysis was calculated by the Mantel-Haenszel method using $1^{\text {st }}$ and $2^{\text {nd }}$ sample sets.

sequencing. For luciferase reporter assay, approximately $2.5 \times 10^{4}$ HeLa cells per well were plated on 24-well plates $24 \mathrm{~h}$ prior to transfection. Cells were transiently transfected using FuGene ${ }^{\circledR} 6$ (Roche, Indianapolis, IN) according to the manufacturer's protocol with $200 \mathrm{ng}$ of DNA plasmid and DNA to Fugene ratio of 3:1. The 40 ng of pRL-TK vector (Promega, Madison, WI) was included in every samples as an internal control to control for transfection efficiencies. The pGL4 vector was also used in parallel as a negative control (Mock). The firefly and Renillalucifease activities were measured $24 \mathrm{~h}$ after transfection, using a dual-luciferase reporter assay system (Promega, Madison, WI) following the manufacturer’s instructions. All experiments were independently performed in triplicate and repeated four times. Additionally, the experiment was also repeated using two additional plasmids constructs containing three copies of the 41-bp oligonucleotides containing either the risk G or the non-risk A allele to confirm the result obtained from constructs containing one copy of the 41-bp oligonucleotide.

\subsection{Statistical Analysis}

For association studies, the allele and genotype distributions in cases and controls were compared and evaluated in allelic, dominant- and recessive-inheritance models by two-tail Fisher's exact test. In the GWAS, SNPs were sorted according to the lowest P-value in one of these models. The Manhattan and quantile-quantile (Q-Q) plots were generated by Haploview version 4.1 [33] and the statistical package R version 2.7.1 [34], respectively. The inflation factor of genomic control ( $\lambda \mathrm{GC}$, the observed median $\chi^{2}$ divided by the expected median value of 0.4549 under the null hypothesis) was also calculated. The Mantel-Haenszel (MH) test for meta-analysis was 
performed only in case of the combined analysis which the combination data of two sample sets were combined and analyzed. For multiple testing, P-value threshold was corrected by Bonferroni correction, in which the conventional significant threshold of 0.05 for single SNP is divided by the total number of SNPs analyzed in a GWAS [35]. Thus, the significant threshold for GWAS was set at $0.05 / 5.35 \times 10^{6}$ or $9.33 \times 10^{-8}$ and for $2^{\text {nd }}$ screening was set at $0.05 / 90$ or $5.56 \times 10^{-4}$. Linkage disequilibrium (LD) structure of the genome was created by Haploview 4.1 to determine the regions containing loci associated with disease risk. For luciferase reporter assays, relative luciferase activities were expressed as fold induction of firefly/Renillaluminescence ratio over control (mock or vector). Differences in relative luciferase activities between the two allele constructs were analyzed by unpaired two-tailed $t$ test and P-value $<0.05$ was considered to be statistically significance.

\section{Results}

\subsection{Genome-Wide Association Study in PTSD}

To identify genetic variants or SNPs associated with PTSD susceptibility, we conducted a genome-wide screening. Cases and controls were divided into two sets. The first set of samples consisted of 396 cases and 457 controls. No cases and controls were classified as outliers in the PCA plot (Figure 1), suggesting that our analysis is not confound by population stratification. Sample call rates of the all subjects were more than 0.99 . Of 600,420 SNPs genotyped, a total of 535,738 autosomal SNPs that passed our initial quality control, with genotype call rate of $\geq 0.99$ in both cases and controls and with PHWE $<0.000001$ in controls, were further analyzed. The Q-Q plot showed that most of observed P-values fit to the expected P-values under the null hypothesis (Figure 2(a)). The $\lambda \mathrm{GC}$ was 1.054 , suggesting low possibility of false-positive associations from population stratification. None of the SNPs achieved bonferroni-corrected genome-wide significance level at $\mathrm{P}<9.33 \times 10^{-8}$ (Figure 2(b)). The lowest P-value from our GWAS finding achieved a P-value of $6.18 \times 10^{-7}$ for an SNP rs1447594 which located around $500 \mathrm{~kb}$ away from the nearest gene (IGSF11; immunoglobulin superfamily, member 11 gene).

\subsection{The $2^{\text {nd }}$ Screening and Combined Analysis}

Top ninety SNPs achieved P-values of less than $1 \times 10^{-4}$ from our GWAS analyses were further evaluated in a second sample set which included 395 cases and 798 controls. Our screening using second sample set revealed suggestive associations of two candidate SNPs with PTSD, rs267950 (rank no. 36) and rs954406 (rank no. 10), which showed P-value of $7.44 \times 10^{-4}$ and $1.00 \times 10^{-3}$ respectively (Table 3). Both sample sets show similar

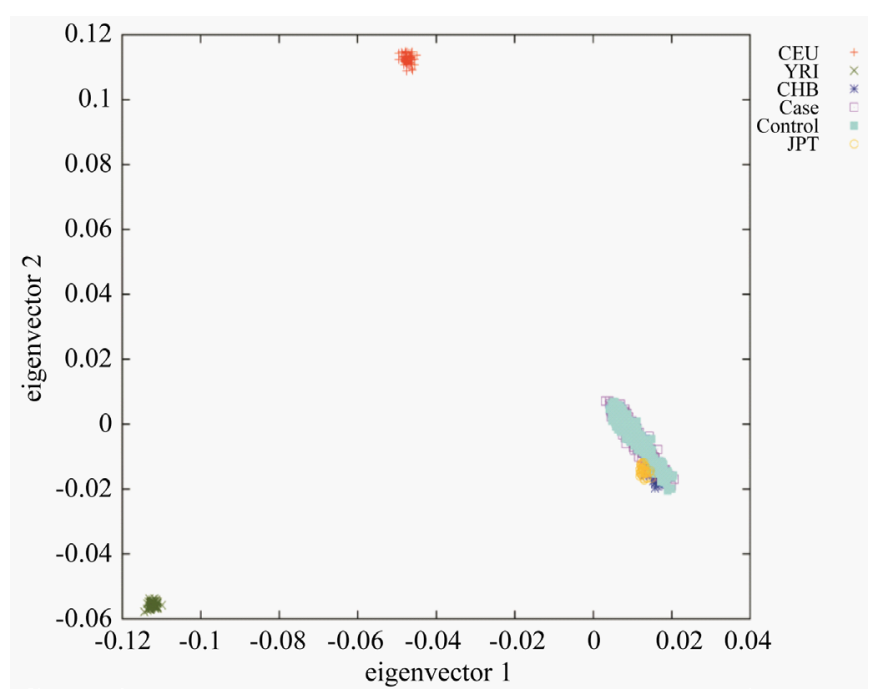

Figure 1. Principle component analysis (PCA) of substructure in a diverse set of East Asian descent (HapMap JPT, CHB and Thai PTSD cases and controls), European descent (CEU) and African descent (YRI). 


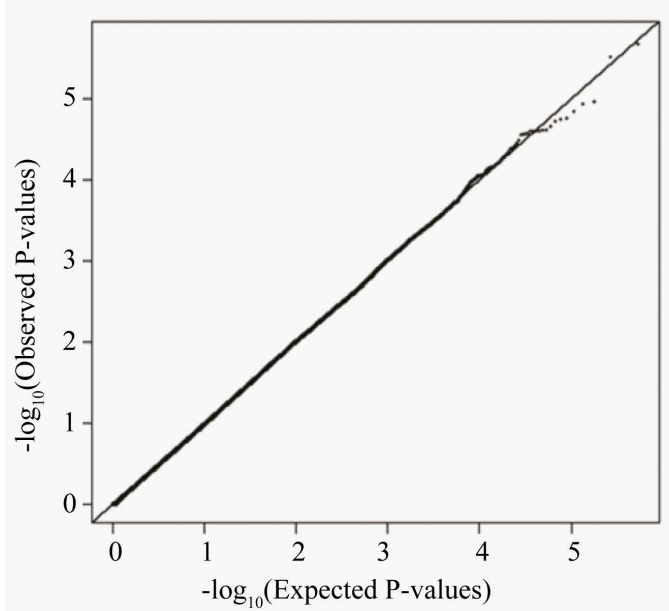

(a)

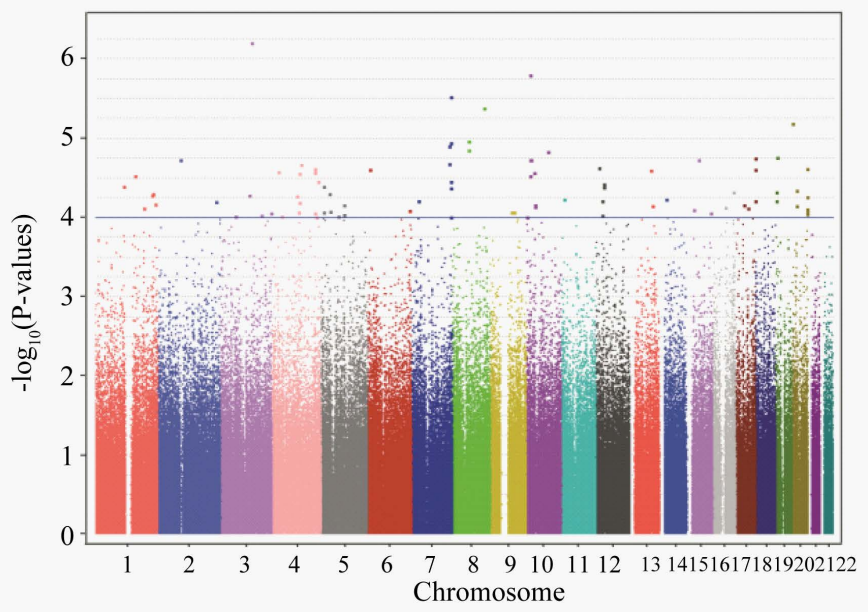

(b)

Figure 2. Overview the results of genome-wide association study for PTSD. (a) The quantile-quantile (Q-Q) plot shows the distribution of observed statistics by allelic test for all utilized 535,738 SNPs from GWAS. The diagonal line shows the values expected under the null hypothesis. The genomic control inflation factor $(\lambda \mathrm{GC})$ was 1.054 , indicating a low possibility of false-positive associations resulting from population stratification in our analysis. (b) The Manhattan plot of all results by chromosome location. The Y axis represents the $-\log _{10}$ of the minimal P-values calculated by Fisher's exact tests for three models: dominant, recessive and allele frequency model.

Table 3. Two candidate SNPs associated with posttraumatic stress disorder in Thai Tsunami survivors.

\begin{tabular}{|c|c|c|c|c|c|c|c|c|c|c|c|c|c|c|c|}
\hline \multirow{3}{*}{ SNP ID } & \multirow{3}{*}{ Study } & \multicolumn{4}{|c|}{ Case } & \multicolumn{4}{|c|}{ Control } & \multirow{2}{*}{$\begin{array}{l}\text { Risk } \\
\text { allele }\end{array}$} & \multicolumn{4}{|c|}{ P-value (Fisher's exact test) } & \multirow{2}{*}{$\begin{array}{l}\text { Odds } \\
\text { ratio }\end{array}$} \\
\hline & & 11 & 12 & 22 & MAF & 11 & 12 & 22 & MAF & & Allele & Genotype & Genotype & minimum & \\
\hline & & & & & & & & & & & 1 vs 2 & $\begin{array}{c}11 \mathrm{vs} \\
12+22\end{array}$ & $\begin{array}{c}22 \text { vs } \\
11+12\end{array}$ & & \\
\hline $\begin{array}{c}\text { rs267950 } \\
{[\mathrm{T} / \mathrm{C}]^{\mathrm{a}}}\end{array}$ & GWAS & 150 & 197 & 49 & 0.372 & 236 & 187 & 34 & 0.279 & $\mathrm{C}$ & $4.05 E-05$ & $6.25 \mathrm{E}-05$ & $2.01 \mathrm{E}-02$ & $4.05 \mathrm{E}-05$ & 1.75 \\
\hline Chr 5 & Replication & 161 & 168 & 66 & 0.380 & 385 & 329 & 82 & 0.310 & $\mathrm{C}$ & $7.44 \mathrm{E}-04$ & $1.36 \mathrm{E}-02$ & $2.03 \mathrm{E}-03$ & $7.44 \mathrm{E}-04$ & 1.36 \\
\hline Position $^{\mathrm{b}}$ & Combined & 311 & 365 & 115 & 0.376 & 621 & 516 & 116 & 0.298 & $\mathrm{C}$ & $3.43 E-07$ & $6.29 \mathrm{E}-06$ & $3.21 \mathrm{E}-04$ & $3.43 \mathrm{E}-07$ & 1.52 \\
\hline $\begin{array}{r}10796433 \\
\text { Gene DPA }\end{array}$ & Meta-analysis $^{c}$ & & & & & & & & & & & & & $1.48 \mathrm{E}-07$ & 1.44 \\
\hline $\begin{array}{c}\text { rs954406 } \\
{[\mathrm{C} / \mathrm{A}]^{\mathrm{a}}}\end{array}$ & GWAS & 174 & 190 & 32 & 0.321 & 269 & 161 & 27 & 0.235 & A & $8.93 E-05$ & $1.48 \mathrm{E}-05$ & $2.25 \mathrm{E}-01$ & $1.48 \mathrm{E}-05$ & 1.83 \\
\hline Chr 10 & Replication & 175 & 178 & 35 & 0.320 & 435 & 302 & 49 & 0.254 & A & $1.01 \mathrm{E}-03$ & $1.00 \mathrm{E}-03$ & $9.18 \mathrm{E}-02$ & $1.00 \mathrm{E}-03$ & 1.51 \\
\hline Position $^{\mathrm{b}}$ & Combined & 349 & 368 & 67 & 0.320 & 704 & 463 & 76 & 0.247 & A & $5.16 \mathrm{E}-07$ & $1.16 \mathrm{E}-07$ & $4.06 \mathrm{E}-02$ & $1.16 \mathrm{E}-07$ & 1.63 \\
\hline $\begin{array}{c}82617594 \\
\text { Gene } \\
\text { LOC647532 }\end{array}$ & Meta-analysis ${ }^{c}$ & & & & & & & & & & & & & $3.97 \mathrm{E}-07$ & 1.44 \\
\hline
\end{tabular}

Overall 95\% CI between 1.07 - 2.40; Chr, chromosome; CI, confidence interval; DAP, death-associated protein; GWAS, Genome-wide association study; MAF, minor allele frequencies; SNP, single nucleotide polymorphism. ${ }^{\mathrm{a}}$ The second allele represents the minor allele; ${ }^{\mathrm{b}}$ From National Center for Biotechnology Information (NCBI) build 36.3 reference; ${ }^{\mathrm{P}} \mathrm{P}$-value and odd ratio for meta-analysis was calculated by the Mantel-Haenszel method using $1^{\text {st }}$ and $2^{\text {nd }}$ sample sets.

direction of association. In addition, both candidate SNPs also showed an improved P-value (from $10^{-5}$ to $10^{-7}$ ) when data were analyzed in combined set of samples using simple combination and meta-analysis (Table 3). However, both SNPs did not reach the bonferroni-corrected significance level for the $2^{\text {nd }}$ screening $(P=5.56 \times$ $10^{-4}$ ). The rs267950 is an intronic SNP within the death-associated protein 1 (DAP1) gene. The rs954406 is not located within any known genes. 


\subsection{Fine Mapping of SNPs around PTSD-Associated Candidate Regions}

After validation of our GWAS finding using the second sample set and by combined analysis, we then focused on two candidate SNPs for our subsequent analyses. The first candidate SNP rs267950 is located in the intron of $D A P 1$ gene and included in a large LD block covering the entire DAP1 gene (Figure 3(a)). The 24 tag SNPs (squared correlation coefficient between the two SNPs $\left(\mathrm{r}^{2}\right)<0.8$, MAF $\left.>0.05\right)$ within the approximately 90-kb LD region including the candidate SNP were selected from the International HapMap Han Chinese (CHB) data and genotyped in both sample sets which consisted of 791 chronic PTSD cases and 1255 controls. No SNP were found to have lower P-value compared to the rs267950. We further genotyped those 18 SNPs that were in complete LD with the rs267950. Genotype distributions of these 18 captured SNPs in cases and controls are shown in Table 2. Among these SNPs, rs267943 showed the lowest P-value $\left(\mathrm{MH}-\mathrm{P}=6.15 \times 10^{-8}\right)$ with an OR of 1.46 (95\% CI, 1.19 - 1.79) and achieved genome-wide significant threshold (Figure 3(b)). We also conducted deep re-sequencing of all four exons of DAP1 gene using sixteen pooled of DNA samples (three subjects per pool) to determine whether there might be harbor the other exonic variations that could be associated with PTSD. The six previously reported SNPs and two novel SNPs were found. However, none of these SNPs were significantly associated with PTSD as shown in Table 4.

The second candidate SNP rs954406 is located on chromosome 10. Fine mapping was carried out using five tag SNPs $\left(\mathrm{r}^{2}<0.8\right.$, MAF $\left.>0.05\right)$ within 53-kb LD region including the candidate SNP. None of these tag SNPs was found to be significantly associated with PTSD. The most significant P-value was rs954406. No other SNPs were found to be completely-linked $\left(r^{2}>0.8\right)$ to rs954406 within this LD block (Figure 3(b)).

\subsection{Transcriptional Activity of rs267943}

To evaluate whether rs267943 could affect DAP1 transcriptional activity, we performed luciferase reporter assay by generating two plasmid constructs containing either the risk allele " $G$ " or non-risk allele "A" of SNP rs267943 on inserted DNA fragments. The basal activity of SV40 promoter for the construct carrying 1-copy of
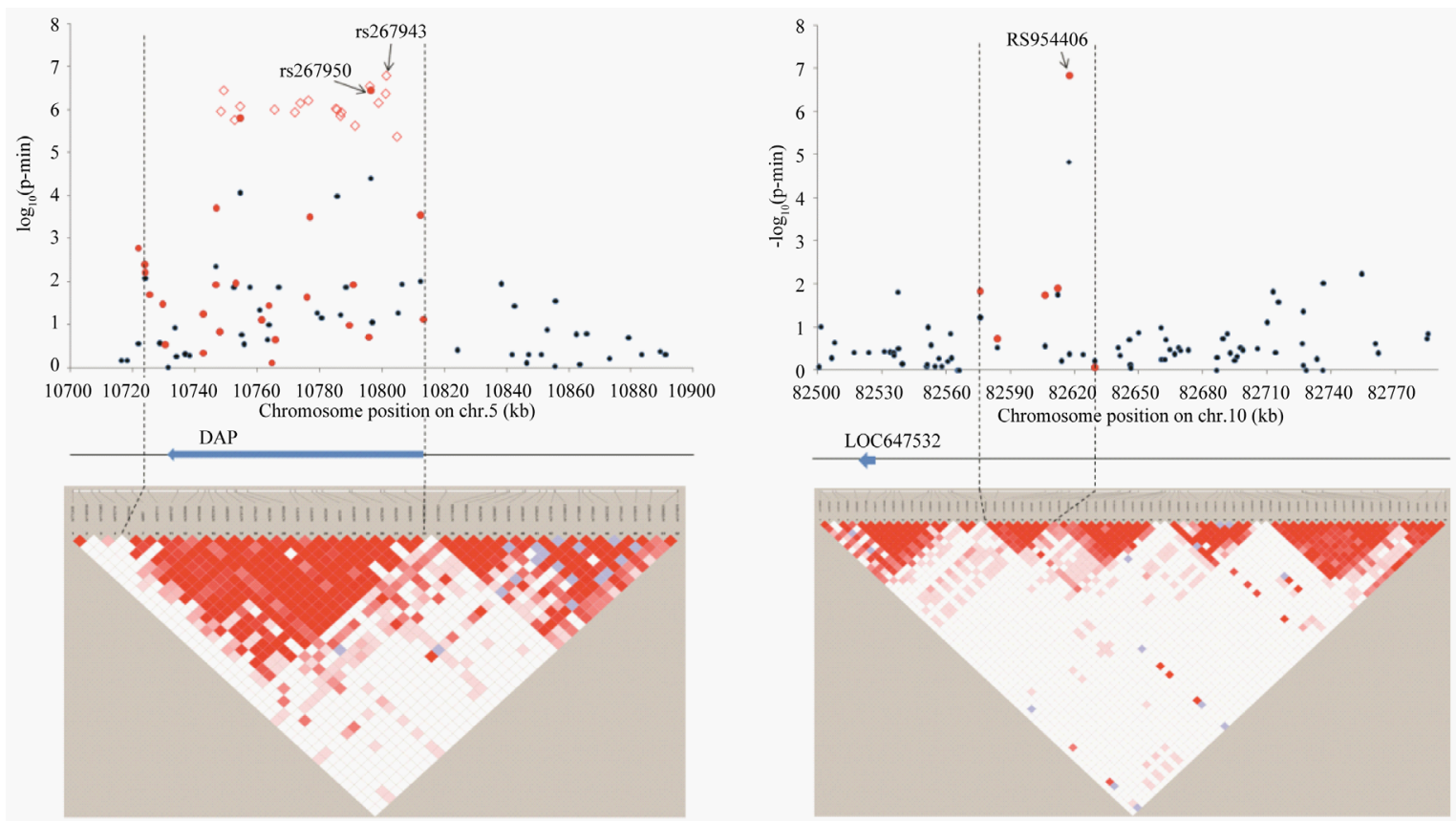

(a)

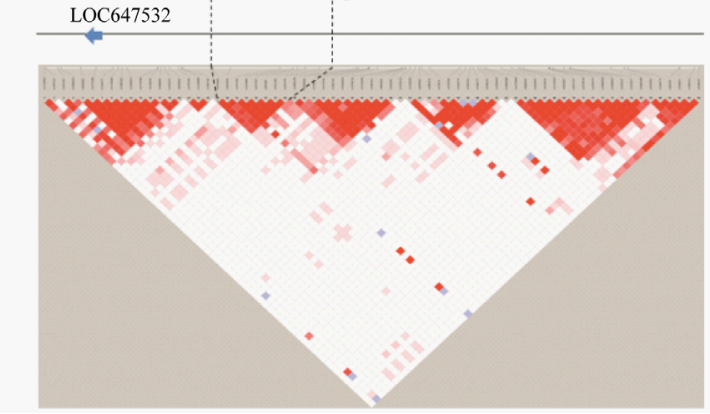

(b)

Figure 3. Case-control association results and linkage disequilibrium map of PTSD-associated candidate regions Casecontrol association plots, genomic structure and linkage disequilibrium (LD) map of (a) 200-kb region surrounding rs267950 on chromosome 5 and (b) rs954406 on chromosome 10. Black dots represent P-value obtained from the genome-wide association study (GWAS). Red dots and open diamonds represent P-value obtained from tag SNPs and SNPs captured by the tag SNPs in fine mapping, respectively. The LD map based on D' was drawn using the genotype data of the cases and the controls in GWAS phase. 
Table 4. Summary of association results of SNPs identified in four exons of DAP1 gene.

\begin{tabular}{|c|c|c|c|c|c|c|c|c|c|c|c|c|c|c|c|c|}
\hline \multirow{2}{*}{ SNP ID } & \multirow{2}{*}{ Position $^{\mathrm{a}}$} & \multirow{2}{*}{ Location } & \multirow{2}{*}{$\begin{array}{c}\text { Allele }^{\mathrm{b}} \\
(1 / 2)\end{array}$} & \multicolumn{4}{|c|}{ Case } & \multicolumn{4}{|c|}{ Control } & \multirow{2}{*}{$\begin{array}{c}\text { Risk } \\
\text { allele }\end{array}$} & \multirow{2}{*}{$\begin{array}{c}\text { P-value } \\
\text { minimum }^{\mathrm{c}}\end{array}$} & \multirow{2}{*}{$\begin{array}{l}\text { Odds } \\
\text { ratio }\end{array}$} & \multirow{2}{*}{$\begin{array}{l}\text { P-value } \\
\text { MH-P }^{d}\end{array}$} & \multirow{2}{*}{$\begin{array}{l}\text { Odds } \\
\text { ratio }\end{array}$} \\
\hline & & & & 11 & 12 & 22 & MAF & 11 & 12 & 22 & MAF & & & & & \\
\hline rs267927 & 10761182 & exon1 & {$[\mathrm{C} / \mathrm{T}]$} & 482 & 269 & 37 & 0.218 & 733 & 429 & 76 & 35 & $\mathrm{C}$ & $1.97 \mathrm{E}-01$ & 1.33 & $1.92 \mathrm{E}-01$ & 1.11 \\
\hline rs5745297 & 10680997 & exon4 & {$[\mathrm{C} / \mathrm{T}]$} & 779 & 10 & 0 & 0.006 & 1239 & 9 & 1 & 0.004 & $\mathrm{~T}$ & $3.57 \mathrm{E}-01$ & 1.59 & $6.71 \mathrm{E}-01$ & 1.34 \\
\hline rs9857 & 10680547 & exon4 & {$[\mathrm{G} / \mathrm{A}]$} & 229 & 399 & 157 & 0.454 & 317 & 644 & 275 & 0.483 & G & $7.55 \mathrm{E}$ & 1.19 & $7.72 \mathrm{E}-02$ & 1.12 \\
\hline rs34974881 & 10680526 & exon4 & {$[\mathrm{G} / \mathrm{A}]$} & 788 & 2 & 0 & & 1247 & 1 & 0 & & A & & 3.16 & $9.01 \mathrm{E}-01$ & 2.31 \\
\hline rs3733765 & 10680491 & exon4 & [G/A] & 758 & 32 & 0 & 0.020 & 1185 & 62 & 1 & 0.026 & G & $2.90 \mathrm{E}-01$ & 1.26 & $4.18 \mathrm{E}-01$ & 1.22 \\
\hline rs1049344 & 10680487 & exon4 & {$[\mathrm{C} / \mathrm{T}]$} & 539 & 212 & 25 & 0.169 & 818 & 368 & 42 & 0.184 & $\mathrm{C}$ & $1.86 \mathrm{E}-01$ & 1.14 & $2.23 \mathrm{E}-01$ & 1.11 \\
\hline Novel1 & 10679912 & exon4 & {$[\mathrm{C} / \mathrm{G}]$} & 788 & 2 & 0 & 0.001 & 1245 & 4 & 0 & 0.002 & $\mathrm{C}$ & $1.00 \mathrm{E}+00$ & 1.27 & $8.15 \mathrm{E}-01$ & 1.74 \\
\hline Novel2 & 10679820 & exon4 & {$[\mathrm{A} / \mathrm{T}]$} & 788 & 2 & 0 & 0.001 & 1245 & 4 & 0 & 0.002 & A & $1.00 \mathrm{E}+00$ & 1.27 & $8.15 E-01$ & 1.74 \\
\hline
\end{tabular}

Chromosome: 5; Gene: DAP; Overall 95\% CI between 0.21 - 34.96; CI, confidence interval; DAP, death-associated protein; MAF, minor allele frequencies; SNP, single nucleotide polymorphism. ${ }^{\mathrm{a}}$ From NCBI build 37.1 reference; ${ }^{\mathrm{b}}$ The second allele represents the minor allele; ${ }^{\mathrm{C}}$ The minimum P-value of Fisher's exact test for three models (dominant, recessive and allelic models); ${ }^{\mathrm{d}} \mathrm{P}$-values and odd ratio for meta-analysis was calculated by the Mantel-Haenszel method using $1^{\text {st }}$ and $2^{\text {nd }}$ sample sets.

$\mathrm{G}$ allele was slightly different from the construct carrying 1-copy of $\mathrm{A}$ allele $\left(\mathrm{P}=1.62 \times 10^{-2}\right)$ (Figure 4). The difference between two allele constructs was confirmed through repeated experiment using 3-copy of $\mathrm{G}$ allele, which found that the basal activity was slightly but significantly higher than that for the construct carrying 3copy of A allele $\left(\mathrm{P}=9 \times 10^{-5}\right)$ (Figure 4$)$.

\section{Discussion}

We reported the first GWAS for PTSD susceptibility in an Asian population using hypothesis-free approach in a large homogenous population from the 2004 Tsunami disaster in the southern part of Thailand. After multiple testing corrections, the strongest signal for association with PTSD susceptibility was observed in rs267943 which achieved a genome-wide significant level $\left(\mathrm{MH}-\mathrm{P}=6.15 \times 10^{-8}\right)$. rs267943 is located within DAP1 on chromosome 5 and could be a novel PTSD susceptibility gene.

PTSD is a multifactorial disease. Several genetics and environmental factors may contribute to the complex etiology of PTSD. Therefore, in this study, we carefully planned and designed our study to avoid errors and discrepancies documented in previous related studies on PTSD genetic factors such as subject selection criteria to better examine how genetic factors can influence the development of PTSD. Only Thai subjects were included in this study to minimize problems with regard to multiple ancestries in the studied population. PCA confirmed the homogeneity of our studied population (Figure 1). Additionally, we also applied rigorous quality control in our GWAS to minimize spurious association from within our data sets (samples and SNPs). Control subjects were carefully selected and included tsunami survivors who experienced similar traumatic events but did not develop PTSD at least six months after the events. Additionally, control populations had similar parameters as case population and were matched for age, sex and trauma exposures. Our study had some potential limitations including male to female ratio and the size of studied population. The male to female ratios in our studied population were slightly different between our data sets as shown in (Table 1). Nonetheless, results obtained from this study should be valid since the ratios were similar. Additionally, study on the contribution of environment and genetic factors on the development of PTSD confirmed that sex plays insignificant role in the development of PTSD. While the study presented in this report may have some potential limitations, our study will provide much needed information for future studies on PTSD in the Thai population.

Two PTSD susceptibility candidate SNPs (rs267950 and rs954406) were detected in our GWAS analysis. Both genes did not reach genome-wide significant level; however, they are likely to be associated with PTSD susceptibility and showed much improved association with PTSD when these SNPs were analyzed in combined sample sets. Previous study showed that GWAS for bipolar disorder combined several small data sets to reach a genome-wide significant level while each small data set showed only suggestive but not significant P-value [36]. It was postulated that GWAS for psychiatric disorders many of true associations (true risk loci) would be 

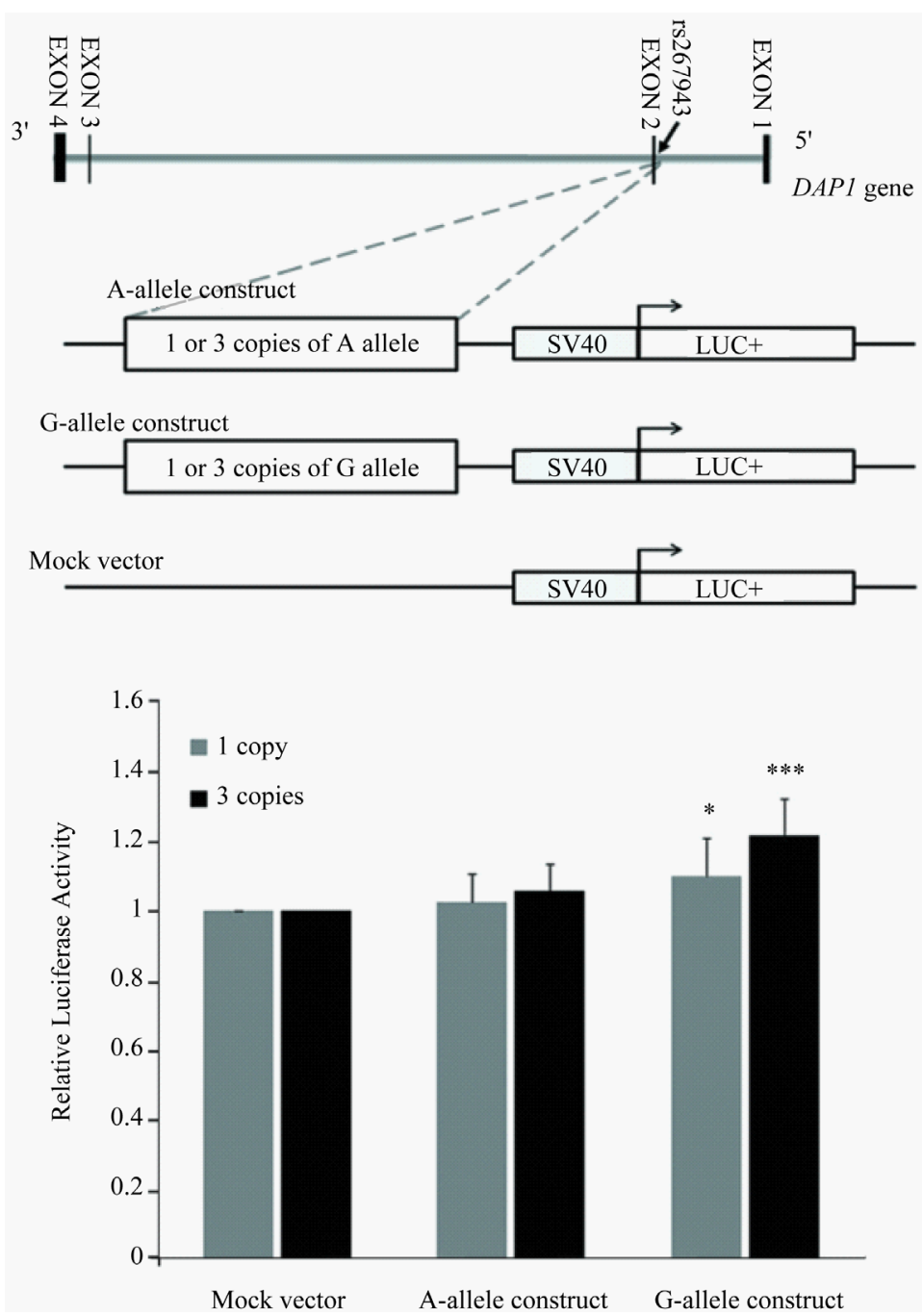

Figure 4. Luciferase reporter gene assay of rs267943, Transiently transfections of mock vector, A- and G-allele constructs were performed in Hela cell line. The firefly luciferase activities were normalizedto Renilla luciferase activities in each experiment. The bars represent the mean \pm S.D. relative luciferase activity of three independent experiments done in quadruplicate. Differences at $\mathrm{P}<0.05$ by Student's t test were considered to be significant. $\left(^{*}\right)$ indicates $\mathrm{P}<0.05$ and $\left({ }^{* * *}\right)$ indicates $\mathrm{P}<0.001$.

contained within the top few hundred or thousand hits of modest significant P-values rather than concentrated within the top few hits of highly significant P-values [37]. A significant level with P-value of less than $10^{-7}$ might be too stringent a criterion to use in single psychiatric disorder GWAS. A rather modest significant level with P-value between $10^{-4}$ to $10^{-7}$ might be sufficient to differentiate true from spurious associations.

All of the PTSD-associated SNPs, including rs267950 and other additional 18 SNPs that were in complete LD with rs267950 (Table 2), were found in the intron of DAP1 gene. However, luciferase reporter promoter analysis of the most significant SNPs, rs267943, showed that rs267943 could affect DAP1 gene expression. To our knowledge, this is the first study revealed a significant association between DAP1 polymorphism and PTSD. Another candidate SNP rs954406 was shown to be significantly associated with PTSD after fine mapping. rs954406 is located over $220 \mathrm{~kb}$ away a gene with unknown function, SH2 domain containing 4B (SH2D4B).

The DAP1 gene, spanning approximately $80 \mathrm{~kb}$, is ubiquitously expressed in various cells and tissues and is expressed as a single $2.4 \mathrm{~kb}$ mRNA encoding a small basic proline-rich protein [38]. DAP1 proteins are highly conserved and orthologs has been identified in most eukaryotic species [39] [40]. Previous studies using immu- 
nostaining and biochemical fractionation revealed that DAP1 localized to the cytoplasm [41]. The involvement of DAP1 in PSTD could be through its role in two evolutionary conserved biological processes, apoptosis and autophagy [38] [40]. The functional relationship between apoptosis and autophagy is complex [42]. Both processes have been implicated in the pathogenesis of many neurodegenerative disorders such as PTSD, Parkinson's, Huntington's and Alzheimer's diseases [43]-[45]. Increasing evidences suggested abnormal cell loss in different parts of the brain in patients with PTSD. Several meta-analysis studies suggested a strong relationship between PTSD and hippocampus atrophy resulted in a significantly smaller hippocampus bilaterally in patients with PTSD as compared to non PTSD patients [46]-[48]. Reduced amygdala volume has been reported in patients with PTSD as compared to trauma-exposed non PTSD patients [48] [49]. Studies suggested that apoptosis could be responsible for the atrophy in hippocampus and in amygdala seen in PTSD patients [50]-[52].

DAP1 was recently identified as a novel substrate for Ser/Thr kinase mammalian target of rapamycin (mTOR) [40], a new target for pharmacological intervention for treatment of PTSD. Systemic inhibition of mTOR by rapamycin following traumatic memory reactivation has been shown to inhibit reconsolidation of fear conditioning in a rat model [53]. Activation of mTOR in the hippocampus [54] or amygdale [55] is required in fear memory acquisition and consolidation. Together, these findings suggested that DAP1, an mTOR substrate, might play an important role in the pathogenesis of PTSD. DAP1 could regulate apoptotic process and memory formation in certain brain regions through mTOR signal transduction. Future studies both in vitro and in vivo into the role of DAP1 in brain will be needed to help establish biological significance of DAP1 in normal brain functions and in neurological disorders such as PTSDs.

Recently, Logue MW, et al. performed GWAS in approximately 500 white and non-Hispanic veterans after combat trauma experience [56] and linked genetic variation in the retinoid-related orphan receptor alpha (RORA) gene to the development of PTSD. The association between RORA genetic variants and PTSD susceptibility was replicated in an African American population. It is interesting that genetic variations identified by Logue, et al [56] are different from genetic variations identified in this study. There are several factors that could contribute to this difference including differences in sample size, ethnicity and type of traumatic event in the study. However, it might be interesting to determine the molecular basis of how both RORA, identified by Logue, et al, and DAP1, identified in this study, could contribute to PTSD susceptibility.

\section{Conclusion}

In conclusion, we conducted the first GWAS for PTSD susceptibility in an Asian population followed by a replicate study and fine mapping in 791 cases and 1255 controls. We demonstrated that rs267943, located within DAP1 gene, had the strongest association with the risk of PTSD and could be a novel PTSD susceptibility gene. Future studies will investigate gene-environmental (GxE) interaction in PTSD to identify all biopsychosocial factors contributing to PTSD susceptibility and bring to preventive strategies. To date, very little is known about the pathogenesis of PTSD. Our study suggested that DAP1 may play a role underlying the pathogenesis of PTSD. Better understanding into the function of DAP1 in brain cell apoptosis and memory reconsolidation in certain regions of the brain will be essential for the development of new drugs or strategies for prevention and treatment of PTSD. Similar GWAS study in different populations will be needed to confirm the association of DAP1 and PTSD susceptibility. The significance of SNPs associated with PTSD identified in this study (Table 3) should be tested in other psychological disorders in the near future to determine whether PTSD susceptibility shares common genetic risk factors with other comorbid diseases.

\section{Acknowledgements}

We would like to acknowledge all staffs in our team and all subjects who participated in this study. Funding for sample collection was provided by grants from Thailand Center of Excellence for Life Sciences (TCELS) and funding for genotyping was supported by RIKEN Yokohama institute.

\section{References}

[1] Kar, N., Mohapatra, P.K., Nayak, K.C., Pattanaik, P., Swain, S.P. and Kar, H.C. (2007) Post-Traumatic Stress Disorder in Children and Adolescents One Year after a Super-Cyclone in Orissa, India: Exploring Cross-Cultural Validity and Vulnerability Factors. BMC Psychiatry, 7, 8. http://dx.doi.org/10.1186/1471-244X-7-8

[2] Lau, J.T., Yu, X., Zhang, J., Mak, W.W., Choi, K.C., Lui, W.W., et al. (2010) Psychological Distress among Adoles- 
cents in Chengdu, Sichuan at 1 Month after the 2008 Sichuan Earthquake. Journal of Urban Health, 87, 504-523. http://dx.doi.org/10.1007/s11524-010-9447-3

[3] Kolaitis, G., Kotsopoulos, J., Tsiantis, J., Haritaki, S., Rigizou, F., Zacharaki, L., et al. (2003) Posttraumatic Stress Reactions among Children Following the Athens Earthquake of September 1999. European Child and Adolescent Psychiatry, 12, 273-280. http://dx.doi.org/10.1007/s00787-003-0339-x

[4] Richardson, L.K., Frueh, B.C. and Acierno, R. (2010) Prevalence Estimates of Combat-Related Post-Traumatic Stress Disorder: Critical Review. Australian and New Zealand Journal of Psychiatry, 44, 4-19. http://dx.doi.org/10.3109/00048670903393597

[5] Zhang, Y. and Ho, S.M. (2011) Risk Factors of Posttraumatic Stress Disorder among Survivors after the 512 Wenchuan Earthquake in China. PloS One, 6, e22371. http://dx.doi.org/10.1371/journal.pone.0022371

[6] Chen, Y.L., Lai, C.S., Chen, W.T., Hsu, W.Y., Wu, Y.C., Wang, P.W., et al. (2011) Risk Factors for PTSD after Typhoon Morakot among Elderly People in Taiwanese Aboriginal Communities. International Psychogeriatrics/IPA, 23, 1686-1691. http://dx.doi.org/10.1017/S1041610211000986

[7] Yehuda, R., Engel, S.M., Brand, S.R., Seckl, J., Marcus, S.M. and Berkowitz, G.S. (2005) Transgenerational Effects of Posttraumatic Stress Disorder in Babies of Mothers Exposed to the World Trade Center Attacks during Pregnancy. The Journal of Clinical Endocrinology and Metabolism, 90, 4115-4118. http://dx.doi.org/10.1210/jc.2005-0550

[8] Fullerton, C.S., Ursano, R.J. and Wang, L. (2004) Acute Stress Disorder, Posttraumatic Stress Disorder, and Depression in Disaster or Rescue Workers. American Journal of Psychiatry, 161, 1370-1376. http://dx.doi.org/10.1176/appi.ajp.161.8.1370

[9] Bendall, S., Alvarez-Jimenez, M., Hulbert, C.A., McGorry, P.D. and Jackson, H.J. (2012) Childhood Trauma Increases the Risk of Post-Traumatic Stress Disorder in Response to First-Episode Psychosis. Australian and New Zealand Journal of Psychiatry, 46, 35-39. http://dx.doi.org/10.1177/0004867411430877

[10] True, W.R., Rice, J., Eisen, S.A., Heath, A.C., Goldberg, J., Lyons, M.J., et al. (1993) A Twin Study of Genetic and Environmental Contributions to Liability for Posttraumatic Stress Symptoms. Archives of General Psychiatry, 50, 257-264. http://dx.doi.org/10.1001/archpsyc.1993.01820160019002

[11] Stein, M.B., Jang, K.L., Taylor, S., Vernon, P.A. and Livesley, W.J. (2002) Genetic and Environmental Influences on Trauma Exposure and Posttraumatic Stress Disorder Symptoms: A Twin Study. The American Journal of Psychiatry, 159, 1675-1681. http://dx.doi.org/10.1176/appi.ajp.159.10.1675

[12] Comings, D.E., Muhleman, D. and Gysin, R. (1996) Dopamine $\mathrm{D}_{2}$ Receptor (DRD2) Gene and Susceptibility to Posttraumatic Stress Disorder: A Study and Replication. Biological psychiatry, 40, 368-372. http://dx.doi.org/10.1016/0006-3223(95)00519-6

[13] Segman, R.H., Cooper-Kazaz, R., Macciardi, F., Goltser, T., Halfon, Y., Dobroborski, T., et al. (2002) Association between the Dopamine Transporter Gene and Posttraumatic Stress Disorder. Molecular Psychiatry, 7, 903-907. http://dx.doi.org/10.1038/sj.mp.4001085

[14] Lee, H.J., Lee, M.S., Kang, R.H., Kim, H., Kim, S.D., Kee, B.S., et al. (2005) Influence of the Serotonin Transporter Promoter Gene Polymorphism on Susceptibility to Posttraumatic Stress Disorder. Depression and Anxiety, 21, 135-139. http://dx.doi.org/10.1002/da.20064

[15] Mellman, T.A., Alim, T., Brown, D.D., Gorodetsky, E., Buzas, B., Lawson, W.B., et al. (2009) Serotonin Polymorphisms and Posttraumatic Stress Disorder in a Trauma Exposed African American Population. Depression and Anxiety, 26, 993-997. http://dx.doi.org/10.1002/da.20627

[16] Morey, R.A., Hariri, A.R., Gold, A.L., Hauser, M.A., Munger, H.J., Dolcos, F., et al. (2011) Serotonin Transporter Gene Polymorphisms and Brain Function during Emotional Distraction from Cognitive Processing in Posttraumatic Stress Disorder. BMC Psychiatry, 11, 76. http://dx.doi.org/10.1186/1471-244X-11-76

[17] Goenjian, A.K., Bailey, J.N., Walling, D.P., Steinberg, A.M., Schmidt, D., Dandekar, U., et al. (2012) Association of TPH1, TPH2, and 5HTTLPR with PTSD and Depressive Symptoms. Journal of Affective Disorders, 140, $244-252$. http://dx.doi.org/10.1016/j.jad.2012.02.015

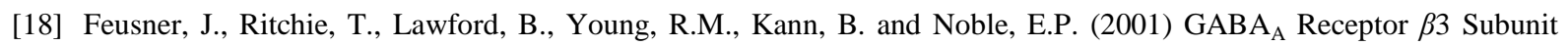
Gene and Psychiatric Morbidity in a Post-Traumatic Stress Disorder Population. Psychiatry Research, 104, 109-117. http://dx.doi.org/10.1016/S0165-1781(01)00296-7

[19] Binder, E.B., Bradley, R.G., Liu, W., Epstein, M.P., Deveau, T.C., Mercer, K.B., et al. (2008) Association of FKBP5 Polymorphisms and Childhood Abuse with Risk of Posttraumatic Stress Disorder Symptoms in Adults. JAMA: The Journal of the American Medical Association, 299, 1291-1305. http://dx.doi.org/10.1001/jama.299.11.1291

[20] Xie, P., Kranzler, H.R., Poling, J., Stein, M.B., Anton, R.F., Farrer, L.A., et al. (2010) Interaction of FKBP5 with Childhood Adversity on Risk for Post-Traumatic Stress Disorder. Neuropsychopharmacology: Official Publication of the American College of Neuropsychopharmacology, 35, 1684-1692. http://dx.doi.org/10.1038/npp.2010.37 
[21] Mehta, D., Gonik, M., Klengel, T., Rex-Haffner, M., Menke, A., Rubel, J., et al. (2011) Using Polymorphisms in FKBP5 to Define Biologically Distinct Subtypes of Posttraumatic Stress Disorder: Evidence from Endocrine and Gene Expression Studies. Archives of General Psychiatry, 68, 901-910. http://dx.doi.org/10.1001/archgenpsychiatry.2011.50

[22] Gelernter, J., Southwick, S., Goodson, S., Morgan, A., Nagy, L. and Charney, D.S. (1999) No Association between $\mathrm{D}_{2}$ Dopamine Receptor (DRD2) “A” System Alleles, or DRD2 Haplotypes, and Posttraumatic Stress Disorder. Biological Psychiatry, 45, 620-625. http://dx.doi.org/10.1016/S0006-3223(98)00087-0

[23] Bachmann, A.W., Sedgley, T.L., Jackson, R.V., Gibson, J.N., Young, R.M. and Torpy, D.J. (2005) Glucocorticoid Receptor Polymorphisms and Post-Traumatic Stress Disorder. Psychoneuroendocrinology, 30, 297-306. http://dx.doi.org/10.1016/j.psyneuen.2004.08.006

[24] Thavichachart, N., Tangwongchai, S., Worakul, P., Kanchanatawan, B., Suppapitiporn, S., Pattalung, A.S., et al. (2009) Posttraumatic Mental Health Establishment of the Tsunami Survivors in Thailand. Clinical Practice and Epidemiology in Mental Health, 3, 5-11. http://dx.doi.org/10.1186/1745-0179-5-11

[25] Davidson, J.R., Book, S.W., Colket, J.T., Tupler, L.A., Roth, S., David, D., et al. (1997) Assessment of a New Self-Rating Scale for Post-Traumatic Stress Disorder. Psychological Medicine, 27, 153-160. http://dx.doi.org/10.1017/S0033291796004229

[26] Blake, D.D., Weathers, F.W., Nagy, L.M., Kaloupek, D.G., Gusman, F.D., Charney, D.S., et al. (1995) The Development of a Clinician-Administered PTSD Scale. Journal of Traumatic Stress, 8, 75-90. http://dx.doi.org/10.1002/jts.2490080106

[27] Pierucci-Lagha, A., Gelernter, J., Chan, G., Arias, A., Cubells, J.F., Farrer, L., et al. (2007) Reliability of DSM-IV Diagnostic Criteria Using the Semi-Structured Assessment for Drug Dependence and Alcoholism (SSADDA). Drug and Alcohol Dependence, 91, 85-90. http://dx.doi.org/10.1016/j.drugalcdep.2007.04.014

[28] Nurnberger Jr, J.I., Blehar, M.C., Kaufmann, C.A., York-Cooler, C., Simpson, S.G., Harkavy-Friedman, J., et al. (1994) Diagnostic Interview for Genetic Studies. Rationale, Unique Features, and Training. NIMH Genetics Initiative. Arch Gen Psychiatry, 51, 849-859.

[29] World Health Organization (1992) The ICD 10-Classification of Mental and Behavioral Disorders: Clinical Descriptions and Diagnostic Guidelines. World Health Organization, Geneva.

[30] Thavichachart, N., Intoh, P., Thavichachart, T., Meksupa, O., Tangwongchai, S., Sughondhabirom, A., et al. (2001) Epidemiological Survey of Mental Disorders and Knowledge Attitude Practice upon Mental Health among People in Bangkok Metropolis. Journal of the Medical Association of Thailand, 84, S118-S126.

[31] Patterson, N., Price, A.L. and Reich, D. (2006) Population Structure and Eigenanalysis. PLoS Genet, 2, e190. http://dx.doi.org/10.1371/journal.pgen.0020190

[32] Ohnishi, Y., Tanaka, T., Ozaki, K., Yamada, R., Suzuki, H. and Nakamura, Y. (2001) A High-Throughput SNP Typing System for Genome-Wide Association Studies. Journal of Human Genetics, 46, 471-477. http://dx.doi.org/10.1007/s100380170047

[33] Barrett, J.C., Fry, B., Maller, J. and Daly, M.J. (2005) Haploview: Analysis and Visualization of LD and Haplotype Maps. Bioinformatics (Oxford, England), 21, 263-265. http://dx.doi.org/10.1093/bioinformatics/bth457

[34] R Development Core Team (2009) R: A Language and Environment for Statistical Computing. R Foundation for Statistical Computing, Vienna. http://www.R-project.org.

[35] Hong, E.P. and Park, J.W. (2012) Sample Size and Statistical Power Calculation in Genetic Association Studies. Genomics \& Informatics, 10, 117-122. http://dx.doi.org/10.5808/GI.2012.10.2.117

[36] Ferreira, M.A., O’Donovan, M.C., Meng, Y.A., Jones, I.R., Ruderfer, D.M., Jones, L., et al. (2008) Collaborative Genome-Wide Association Analysis Supports a Role for ANK3 and CACNA1C in Bipolar Disorder. Nature Genetics, 40, 1056-1058. http://dx.doi.org/10.1038/ng.209

[37] Craddock, N., O’Donovan, M.C. and Owen, M.J. (2008) Genome-Wide Association Studies in Psychiatry: Lessons from Early Studies of Non-Psychiatric and Psychiatric Phenotypes. Molecular Psychiatry, 13, 649-653. http://dx.doi.org/10.1038/mp.2008.45

[38] Deiss, L.P., Feinstein, E., Berissi, H., Cohen, O. and Kimchi, A. (1995) Identification of a Novel Serine/Threonine Kinase and a Novel 15-kD Protein as Potential Mediators of the Gamma Interferon-Induced Cell Death. Genes \& Development, 9, 15-30. http://dx.doi.org/10.1101/gad.9.1.15

[39] Gonzalez-Estevez, C., Felix, D.A., Aboobaker, A.A. and Salo, E. (2007) Gtdap-1 Promotes Autophagy and Is Required for Planarian Remodeling during Regeneration and Starvation. Proceedings of the National Academy of Sciences of the United States of America, 104, 13373-13378. http://dx.doi.org/10.1073/pnas.0703588104

[40] Koren, I., Reem, E. and Kimchi, A. (2010) DAP1, a Novel Substrate of mTOR, Negatively Regulates Autophagy. Current Biology, 20, 1093-1098. http://dx.doi.org/10.1016/j.cub.2010.04.041

[41] Kimchi, A. (1998) DAP Genes: Novel Apoptotic Genes Isolated by a Functional Approach to Gene Cloning. Biochi- 
mica et Biophysica Acta (BBA)-Reviews on Cancer, 1377, F13-F33. http://dx.doi.org/10.1016/s0304-419x(98)00002-X

[42] Maiuri, M.C., Zalckvar, E., Kimchi, A. and Kroemer, G. (2007) Self-Eating and Self-Killing: Crosstalk between Autophagy and Apoptosis. Nature Reviews Molecular Cell Biology, 8, 741-752. http://dx.doi.org/10.1038/nrm2239

[43] Vila, M. and Przedborski, S. (2003) Neurological Diseases:Targeting Programmed Cell Death in Neurodegenerative Diseases. Nature Reviews Neuroscience, 4, 365-375. http://dx.doi.org/10.1038/nrn1100

[44] Nixon, R.A. (2006) Autophagy in Neurodegenerative Disease: Friend, Foe or Turncoat? Trends in Neurosciences, 29, 528-535. http://dx.doi.org/10.1016/j.tins.2006.07.003

[45] Levine, B. and Kroemer, G. (2008) Autophagy in the Pathogenesis of Disease. Cell, 132, 27-42. http://dx.doi.org/10.1016/j.cell.2007.12.018

[46] Kitayama, N., Vaccarino, V., Kutner, M., Weiss, P. and Bremner, J.D. (2005) Magnetic Resonance Imaging (MRI) Measurement of Hippocampal Volume in Posttraumatic Stress Disorder: A Meta-Analysis. Journal of Affective Disorders, 88, 79-86. http://dx.doi.org/10.1016/j.jad.2005.05.014

[47] Smith, M.E. (2005) Bilateral Hippocampal Volume Reduction in Adults with Post-Traumatic Stress Disorder: A Meta-Analysis of Structural MRI Studies. Hippocampus, 15, 798-807. http://dx.doi.org/10.1002/hipo.20102

[48] Karl, A., Schaefer, M., Malta, L.S., Dorfel, D., Rohleder, N. and Werner, A. (2006) A Meta-Analysis of Structural Brain Abnormalities in PTSD. Neuroscience \& Biobehavioral Reviews, 30, 1004-1031. http://dx.doi.org/10.1016/j.neubiorev.2006.03.004

[49] Rogers, M.A., Yamasue, H., Abe, O., Yamada, H., Ohtani, T., Iwanami, A., et al. (2009) Smaller Amygdala Volume and Reduced Anterior Cingulate Gray Matter Density Associated with History of Post-Traumatic Stress Disorder. Psychiatry Research: Neuroimaging, 174, 210-216. http://dx.doi.org/10.1016/j.pscychresns.2009.06.001

[50] Zhang, L., Zhou, R., Li, X., Ursano, R.J. and Li, H. (2006) Stress-Induced Change of Mitochondria Membrane Potential Regulated by Genomic and Non-Genomic GR Signaling: A Possible Mechanism for Hippocampus Atrophy in PTSD. Medical Hypotheses, 66, 1205-1208. http://dx.doi.org/10.1016/j.mehy.2005.11.041

[51] Li, X.M., Han, F., Liu, D.J. and Shi, Y.X. (2010) Single-Prolonged Stress Induced Mitochondrial-Dependent Apoptosis in Hippocampus in the Rat Model of Post-Traumatic Stress Disorder. Journal of Chemical Neuroanatomy, 40, 248255. http://dx.doi.org/10.1016/j.jchemneu.2010.07.001

[52] Ding, J., Han, F. and Shi, Y. (2010) Single-Prolonged Stress Induces Apoptosis in the Amygdala in a Rat Model of Post-Traumatic Stress Disorder. Journal of Psychiatric Research, 44, 48-55. http://dx.doi.org/10.1016/j.jpsychires.2009.06.001

[53] Blundell, J., Kouser, M. and Powell, C.M. (2008) Systemic Inhibition of Mammalian Target of Rapamycin Inhibits Fear Memory Reconsolidation. Neurobiology of Learning and Memory, 90, 28-35. http://dx.doi.org/10.1016/j.nlm.2007.12.004

[54] Bekinschtein, P., Katche, C., Slipczuk, L.N., Igaz, L.M., Cammarota, M., Izquierdo, I., et al. (2007) mTOR Signaling in the Hippocampus Is Necessary for Memory Formation. Neurobiology of Learning and Memory, 87, 303-307. http://dx.doi.org/10.1016/j.nlm.2006.08.007

[55] Parsons, R.G., Gafford, G.M. and Helmstetter, F.J. (2006) Translational Control via the Mammalian Target of Rapamycin Pathway Is Critical for the Formation and Stability of Long-Term Fear Memory in Amygdala Neurons. The Journal of Neuroscience, 26, 12977-12983. http://dx.doi.org/10.1523/JNEUROSCI.4209-06.2006

[56] Logue, M.W., Baldwin, C., Guffanti, G., Melista, E., Wolf, E.J., Reardon, A.F., et al. (2013) A Genome-Wide Association Study of Post-Traumatic Stress Disorder Identifies the Retinoid-Related Orphan Receptor Alpha (RORA) Gene as a Significant Risk Locus. Molecular Psychiatry, 18, 937-942. 


\section{Abbreviations}

CI, Confidence Interval;

Chr, Chromosome;

DAP, Death-Associated Protein;

GWAS, Genome-Wide Association Study;

LD, Linkage Disequilibrium;

MAF, Minor Allele Frequencies;

MH, Mantel-Haenszel Method;

OR, Odds Ratio;

P, P-Value;

PTSD, Posttraumatic Stress Disorder;

S.D., Standard Deviation;

SNP, Single Nucleotide Polymorphism. 